\title{
Influence of knowledge sharing behaviour \& social intelligence on teaching and learning performance: evidence from Malaysian Private Universities
}

\begin{abstract}
Academicians knowledge sharing behaviour and social intelligence plays an essential role in enhancing their teaching and learning performance. Nevertheless, empirical studies that link these concepts are scarce. This paper aims to examine the influence of knowledge sharing behaviour and social intelligence on teaching and learning performance among academicians in Malaysian Private Universities. A questionnaire-based survey was carried out among academicians in the School of Business from seven Malaysian private universities in the Klang Valley area. The survey yielded 318 responses. The results were analysed using Statistical Package for the Social Science (SPSS) version 22 for Windows software.Specifically, the relationship between (1) knowledge sharing behavior and teaching and learning performance (2) social intelligence and teaching and learning performance and (3) social intelligence and knowledge sharing behaviour are being proposed in this study. Moreover, this study is expected to contribute to the following: (1) Malaysian Private Universities in the formation of an ideal model for academicians, (2) body of knowledge, specifically in the field of teaching and learning performance in Malaysian Private Universities and (3) literature in human resources pertaining to knowledge sharing behavior, social intelligence and teaching and learning performance.
\end{abstract}

Keyword: Knowledge sharing behavior; Social intelligence; Teaching and learning performance; Malaysian Private Universities 